\title{
Editorial
}

E ste número de Akademos presenta un conjunto de artículos que exponen los avances de las investigaciones del equipo del Centro de Investigaciones en Ciencias y Humanidades, un equipo multidisciplinario, que comprende diversos campos de las ciencias, las artes y las humanidades. Los trabajos fueron expuestos en la Jornada de Conversatorios en Ciencias y Humanidades (agosto-octubre 2017), realizada en el marco del 40 aniversario de nuestra universidad, y por medio de la cual nuestro Centro se sumó a la celebración. De este modo, en esta jornada que duró 10 semanas, cada investigador conversó con especialistas invitados sobre las investigaciones que desarrolla actualmente.

Iniciamos con el primer artículo, titulado La poesía de David Escobar Galindo: un viaje por sus textos esenciales, trabajo realizado por el joven investigador del $\mathrm{CICH}$ en literatura Mario Sermeño Zetino, quien dio a conocer los avances de la compilación de una poesía escogida y del estudio interpretativo sobre la obra poética de uno de los principales íconos de la literatura salvadoreña, David Escobar Galindo, con quien seguidamente conversó sobre esta selección poética. Es un estudio con mucha minuciosidad, impecable, que se nutrió aún más por los aportes del poeta Escobar Galindo, que salieron a la luz durante el conversatorio.

Luego encontramos el trabajo del economista Mauricio González Orellana, quien nos presenta su conversatorio sobre Educación y crecimiento en El Salvador. El contenido del artículo de esta edición es igualmente producto de la investigación y de los aportes que surgieron durante el conversatorio, que el autor sostuvo con el Dr. Óscar Cabrera, Presidente del Banco Central de Reserva.

El tercer artículo se titula El èthos tradicional. Estudio sobre ética antigua, investigación que lleva a cabo David Ernesto López. Lo acompañó en el conversatorio el máster Jaime Escalante, con quien el autor compartió sobre temas de filosofía moral clásica y aquellos elementos culturales que el discurso posmoderno llama metarrelatos o grandes relatos.

Continuando con el cuarto artículo, Oscar Picardo Joao, director del CICH, efectuó una reseña sobre Los aportes del CICH a la teoría educativa, contribuciones que en materia teórica el Centro a ha dado a través de diferentes publicaciones, como por ejemplo el Diccionario Enciclopédico en 
Ciencias de la Educación, y en materia curricular, una propuesta para la aplicación del modelo pedagogical growth curve, sustentada en investigaciones de campo e implementación de proyectos. Este tema fue conversado con el Lic. Juan Carlos Escobar Baños.

El quinto aporte en esta jornada académica es la conferencia magistral de nuestro distinguido investigador Matías Romero, titulada 15 de septiembre: moral, civismo y cultura nacional, en la que realiza reflexiones sobre los valores éticos, culturales y cívicos de los salvadoreños.

\section{La calidad de la educación artística en} la formación docente se tituló el conversatorio de Marta Eugenia Valle Contreras, en el que la autora conversó con la Mtr. Sara María Boulogne, coordinadora del Programa de Formación en Educación Artística para Docentes en Servicio (MINEDFEPADE), sobre el papel de la formación docente en la calidad de la educación artística, los recorridos y desafíos que esta área importantísima de la educación tiene en nuestro país.

Continúa esta edición el artículo Metodología del diseño arquitectónico. Aplicaciones para el cambio climático en E1 Salvador, de Jaime E. Escobar Salmerón, que junto con el Arq. Jorge Luis Hernández, ex rector de la Universidad Albert Einstein, conversó sobre el horizonte metodológico del ejercicio arquitectónico, tomando en cuenta los efectos inmediatos del cambio climático global.

El penúltimo artículo corresponde al tema de La Tisuloterapia de Javier Urrutia García, que junto a la invitada especial de la jornada, la Dra. Marie Christine Scholler, ex decana de la Facultad de Medicina Natural de la Universidad de la Sorbona, conversó sobre las bases teóricas y los alcances posibles de la Tisuloterapia, tratamiento para enfermedades degenerativas.

Cerramos la edición con el artículo Oportunidades y desafíos de la pesca y la acuicultura de El Salvador, elaborado por Ana Ruth Hidalgo Bonilla, avance de su investigación acerca de este importante tema, el cual discutió con el Ing. Jorge López Padilla, académico de la Facultad de Agricultura e Investigación Agrícola de la UJMD.

Esta entrega de artículos, contrastados y validados por especialistas, es parte del quehacer del CICH como unidad de desarrollo y difusión de investigación científica. Invitamos a la comunidad académica y científica a seguir avanzando en la creación y el debate del conocimiento, de tal forma que esta práctica sea de impacto en los distintos sectores educativos, sociales y productivos de nuestro país.

\section{Consejo Editorial}

